\title{
Comparison of the effects of hyaluronidase and hyaluronic acid on probiotics growth
}

\author{
Alessandro Di Cerbo ${ }^{1 *}$, Maria Aponte ${ }^{2}$, Rita Esposito ${ }^{1}$, Moreno Bondi $^{3}$ and Beniamino Palmieri ${ }^{1}$
}

\begin{abstract}
Background: Hyaluronic acid has several clinical applications. Recent evidences suggested antimicrobial properties against several pathogens. The aim of the present survey was to evaluate the effect of hyaluronic acid, alone or in combination with hyaluronidase, on protechnological or probiotic strains.

Results: The role of hyaluronic acid and hyaluronidase on in vitro growth rate of different lactic acid bacteria was investigated. Standard methods revealed that low concentrations of hyaluronic acid $\left(0.5-0.125 \mathrm{mg} \mathrm{ml}^{-1}\right)$, and hyaluronidase at fixed concentration $\left(1.6 \mathrm{mg} \mathrm{m}^{-1}\right)$, resulted in an increased bacterial strains growth up to 72 hours whereas higher concentrations of the acid $\left(2\right.$ and $\left.1 \mathrm{mg} \mathrm{m}^{-1}\right)$, and hyaluronidase at the same fixed concentration, reduced the bacterial growth.
\end{abstract}

Conclusions: Observations might suggest a possible protective role of both hyaluronidase and low doses of hyaluronic acid towards some strains, supporting their in vivo proliferation and engraftment after oral administration. Hyaluronidase introduction into growth medium greatly enhanced the bacterial growth up to 72 hours.

Keywords: Hyaluronic acid, Hyaluronidase, Lactic acid bacteria

\section{Background}

Hyaluronic acid (HA), a large linear glycosaminoglycan which is mostly present within extracellular matrix and whose molecular weight ranges from $8 \times 10^{5}$ (LMWHA) to $2 \times 10^{6}$ (HMWHA) Da [1], is a chain of repeating disaccharide units of $\mathrm{D}$-glucuronic acid and $\mathrm{N}$-acetyl-D-glucosamine [2]. HA is involved in biological and pathological processes such as cell adhesion, migration, proliferation, differentiation [3], vascular diseases and lymphocyte trafficking [4,5].

HA Anti-inflammatory action [6,7], bacteriostatic effect [8] and antioxidant properties [9] have been recently highlighted with a wide range of potential therapeutic perspectives such as oral, pneumological, dermatological and urological areas [10]. Healing properties of degradation products of HA achieved by $\mathrm{N}$-acetylglucosaminic bonds breakdown, catalysed by the hyaluronidases, have been also well described in the literature [11]. Hyaluronidase (Hy), "hydrolases" with a molecular weight of approximately $60000 \mathrm{Da}$, has been widely used in medicine due to its ability to reduce extravasation injuries [12], to temporarily

\footnotetext{
* Correspondence: alessandro811@hotmail.it

'Dipartimento di Chirurgia Generale e Specialità Chirurgiche, Università degli Studi di Modena e Reggio Emilia, via del pozzo 71 41124, Modena, Italy Full list of author information is available at the end of the article
}

liquefy hyaluronic acid increasing the permeability of vessel membranes [13] and, as recently observed in Watanabe heritable hyperlipidaemic rabbits, to cause a partial disruption of the atherosclerotic plaque surfaces [14]. The hyaluronidases can be subdivided into three types [15]: 1) hyaluronate-4-glycanohydrolases (EC 3.2.1.35), that are present in mammalian spermatozoa, lysosomes and the venoms of various insects and snakes; 2) hyaluronate-3glycanohydrolases (EC 3.2.1.36), that are produced by leeches and some hookworms and 3) bacterial hyaluronidases or hyaluronate lyases (EC 4.2.2.1 or EC 4.2.99.1).

Commonly used hyaluronidases are the partially purified bovine and ovine testicular ones. In spite of such a wide employment of both HA and Hy, only a few studies have been conducted to assess their possible combined effects, if any, on protechnological or probiotic bacteria. Based on the survey of Ardizzoni et al. (2011) [8], focused on the inhibitory effect of HA on a group of pathogenic bacteria and fungal strains, the aim of the present study was to evaluate the effects of HA on potential probiotic Lactic Acid Bacteria (LAB). 


\section{Results and discussion}

$\mathrm{LAB}$ engraftment within human gut has been the main challenge of last decade. However, well standardized procedures to achieve a long lasting engraftment still lack. This study, has been focused upon HA- Hy - LAB interaction to promote bacterial engraftment and feeding in order to enhance and prolong their beneficial effects. Firstly, the antimicrobial effect of HA was evaluated by MIC test in MRS agar. Among strains listed in Table 1, no one proved to be inhibited by HA even at a concentration of $4 \mathrm{mg} \mathrm{ml}^{-1}$. $\mathrm{pH}$ values of HA dilutions ranged from 6.5 to 7.6 , corresponding to an HA concentration of 4 and $0.0625 \mathrm{mg} \mathrm{ml}^{-1}$, respectively. Moreover, when Lactobacillus (Lb.) rhamnosus LbGG cells were exposed, for $30 \mathrm{~min}$, to different levels of HA (4-0.0625 mg ml${ }^{-1}$ ) a slight increase (about $0.5 \log \mathrm{CFU} \mathrm{m} \mathrm{m}^{-1}$ ) in microbial counts was recorded (data not shown). In other words, high molecular weight HA did not exert any antimicrobial activity when tested on several LAB strains, but, on contrary, it seemed to enhance the bacterial viability.

To better understand the - strains viability improvement, the ability to ferment HA and its precursor was evaluated by assessment of $\mathrm{pH}$ lowering according to a conventional procedure. All tested strains, namely three urease positive streptococci [19] and LbGG, proved to be able to utilize N-acetyl-D glucosamine, but not Dglucuronic acid as well as HA.

LbGG is a probiotic strain able to survive to $30 \mathrm{~min}$ of exposure to simulated gastric juice but not to $90 \mathrm{~min}$ [20]. Strain's survival, evaluated in presence of increasing concentration of HA $\left(0.0125-1.6 \mathrm{mg} \mathrm{ml}^{-1}\right)$ to simulated gastric juice for $90 \mathrm{~min}$, highlighted a weak positive gastro-protective effect that appeared directly correlated to HA concentration: 1) At 1.6 and $0.8 \mathrm{mg} \mathrm{ml}^{-1} \mathrm{HA}$ a five $\log$ of reduction (from 7 to $2 \mathrm{CFU} \mathrm{ml}{ }^{-1}$ ) was recorded; 2) At 0.4 and $0.2 \mathrm{mg} \mathrm{ml}^{-1} \mathrm{HA}$ a $5.5 \mathrm{Log}$ reduction (from 7 to $1.5 \mathrm{CFU} \mathrm{ml}^{-1}$ ) was recorded; 3) At HA concentration lower than $0.1 \mathrm{mg} \mathrm{ml}^{-1}$ no strain survival

Table 1 Strains used in this study and source of isolation

\begin{tabular}{llll}
\hline Taxon & Strain & Source & Reference \\
\hline Lb. rhamnosus & LbGG & American Type Culture Collection & ATCC53103 \\
Lb. casei & 491 & Provolone del Monaco cheese & {$[16]$} \\
Lb. casei & 496 & Provolone del Monaco cheese & {$[16]$} \\
Lb. pentosus & OM13 & Table olives & {$[17]$} \\
Lb. rhamnosus & VT1 & Parmigiano Reggiano cheese & {$[18]$} \\
Lb. rhamnosus & RBM526 & Parmigiano Reggiano cheese & {$[18]$} \\
Lb. rhamnosus & RBT739 & Parmigiano Reggiano cheese & {$[18]$} \\
St. macedonicus & 67 & Provolone del Monaco cheese & {$[19]$} \\
St. thermophilus & 309 & Provolone del Monaco cheese & {$[19]$} \\
St. thermophilus & 247 & Provolone del Monaco cheese & {$[19]$} \\
St. thermophilus & $82 A$ & Provolone del Monaco cheese & {$[19]$} \\
\hline
\end{tabular}

was detected. At the used concentrations, HA is not able to protect the probiotic strain $L b$. rhamnosus GG during a 90 minutes long exposition to simulated gastric juice, but further studies would be useful to understand if results may be improved by considering higher concentration of HA.

A widely accepted in vitro system, which allows simultaneous evaluation of several HA doses, was compared with an innovative method based on the old concept of dynamic light scattering. By these two approaches comparable kinetic curves were obtained. Firstly, tests were performed on three selected urease positive strains belonging to Streptococcus (St.) thermophilus species in presence of growing concentrations of HA, until $48 \mathrm{~h}$. As shown in Figure 1, each strain displayed a recurrent trend in the O.D. kinetics. In detail, curve profiles dropped after $24 \mathrm{~h}$ in all cases, showing a higher marked decrease when HA concentration was higher. When lower concentrations of HA were used, O.D. decrease was limited. Strain $82 \mathrm{~A}$ behaved as 247 and therefore was not shown.

Streptococci were even employed for the same set of trials previously described, but in presence of both HA and Hy. According to obtained data (Figure 2), strains displayed after $24 \mathrm{~h}$ a completely different behavior: strains 309 and 247 exhibited an O.D. increase, above all in presence of higher concentrations of HA, indicating a bacterial growth enhancement.

Monitoring strains' activity up to 72 hours revealed a slight increase of the slope, except in presence of the highest HA concentration. As shown in Figure 3, each strain displayed the same trend at the highest HA concentration. The curve profile of each strain at $2 \mathrm{mg} \mathrm{mL}^{-1}$ of HA showed a slight decrease after $24 \mathrm{~h}$ as for higher HA concentration. At lower HA concentrations both a little O.D. increase for 82A strain and a slight O.D. increase for 309 and 247 strains were observed.

These preliminary experiments, demonstrated that bacterial growth may be influenced by HA concentration, by Hy concentration and by both of them.

Standard method indicated that a bacterial growth inhibition was observable when $\mathrm{HA}$, along with $\mathrm{Hy}$, was used at concentrations ranging from 2 to $1 \mathrm{mg} \mathrm{ml}^{-1}$. When considering higher HA concentrations (ranging from 0.5 to $0.125 \mathrm{mg} \mathrm{ml}^{-1}$ ), along with $\mathrm{Hy}$, a growth stimulation up to 72 hours was observed. These results provide interesting insights about LAB growth kinetics, and highlight a possible synergistic role of the two challenged molecules that is likely to be related to the ability of LAB strains to use the N-acetyl-D glucosamine monomer as carbon source.

Although speculative, a possible combined role of HA and hyaluronidase on the bacterial growth was already hypothesized by Starr et al. (2006) [21]. Hy Streptococcus (St.) 

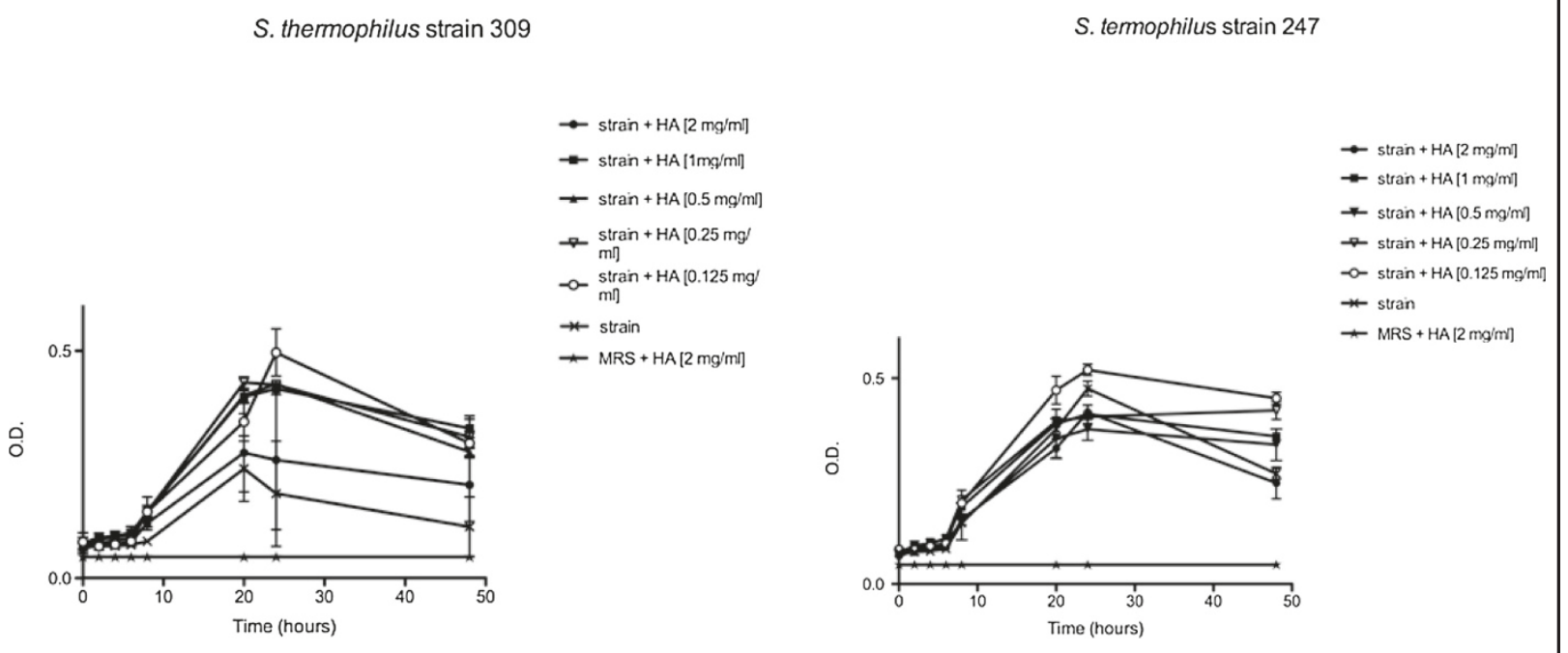

\begin{tabular}{lccccccc}
\hline \multirow{2}{*}{ Strain } & 2 & 4 & 6 & 8 & 20 & 24 & 48 \\
\cline { 2 - 9 } & - & - & $* *$ & $* *$ & $* *$ & $* *$ & $* *$ \\
\hline 309 & - & $* *$ & $* *$ & $* *$ & $*$ & $* *$ & $* *$ \\
\hline 247 & - & $* *$ & $* *$ & $* *$ & $*$ & $* *$ & $* *$ \\
\hline $82 \mathrm{~A}$ & & & $*$ & $*$ & $*$ & $*$ \\
\hline
\end{tabular}

Figure 1 Effects of HA on St. thermophilus strains 309 and 247 until 48 h. Bacteria were employed at a starting concentration of

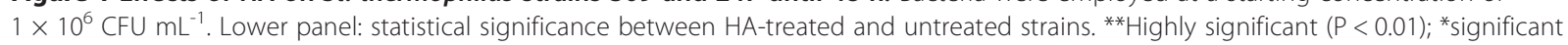
$(P<0.05)$; - not significant $(P>0.05)$.

pyogenes was shown to grow with $\mathrm{N}$-acetylglucosamine but not with D-glucuronic acid as a sole carbon source. The same metabolic behavior was recorded in protechnological and probiotic LAB during this study. Only $\mathrm{Hy}^{+}$strains could grow utilizing HA, as a sole carbon source, suggesting that Hy could permit the strain to utilize host HA as an energy source.

In conclusion, especially high HA concentrations seem to inhibit bacterial growth, however when low HA concentrations are combined with Hy the bacterial growth seems to be enhanced even beyond 72 hours.

Further studies, in order to understand if the effects of $\mathrm{HA}$ and Hy are strain specific as they seems to be, are urgently required; specifically, a wider screening of different $\mathrm{LAB}$ with interesting features, such as urease positive and/or hyaluronidase activity, might help to outline a new probiotic oral formula with enhanced prebiotic gut adherence properties and more effective therapeutic effect.

\section{Conclusions}

The effect of hyaluronic acid on protechnological or probiotic bacteria has never been evaluated before. In this study, the effect of hyaluronic acid, alone or in combination with hyaluronidase, on three streptococci and one probiotic Lactobacillus strain was assessed. By obtained evidences, a synergistic role of the two molecules was described: when low hyaluronic acid concentrations are combined with hyaluronidase, the bacterial growth appeared greatly enhanced even beyond 72 hours. This phenomenon could be related to ability of tested strains to metabolize N-acetyl-D glucosamine, one of the precursor of hyaluronic acid.

\section{Methods}

\section{Media and reagents}

MRS (Oxoid LTD, Basingstoke, Hampshire, U.K.) was employed for bacterial strains growth, strain maintenance and viable count assessment. Sterile saline solutions of High Molecular Weight HA (1837 kDa, $8 \mathrm{mg} \mathrm{ml}^{-1}$ ) where kindly provided by IBSA (Institute Biochemique $\mathrm{SA}$, Lugano, $\mathrm{CH}$ ). Hyaluronidase solution (Jaluronidasi 100 I.U., $3.2 \mathrm{mg} \mathrm{ml}^{-1}$ ) was purchased from Farmacia Testi snc, Milan, Italy.

\section{Evaluation of minimal inhibitory concentration for HA}

Dilutions for HA MIC determination were performed in sterile deionized water with concentrations ranging from 


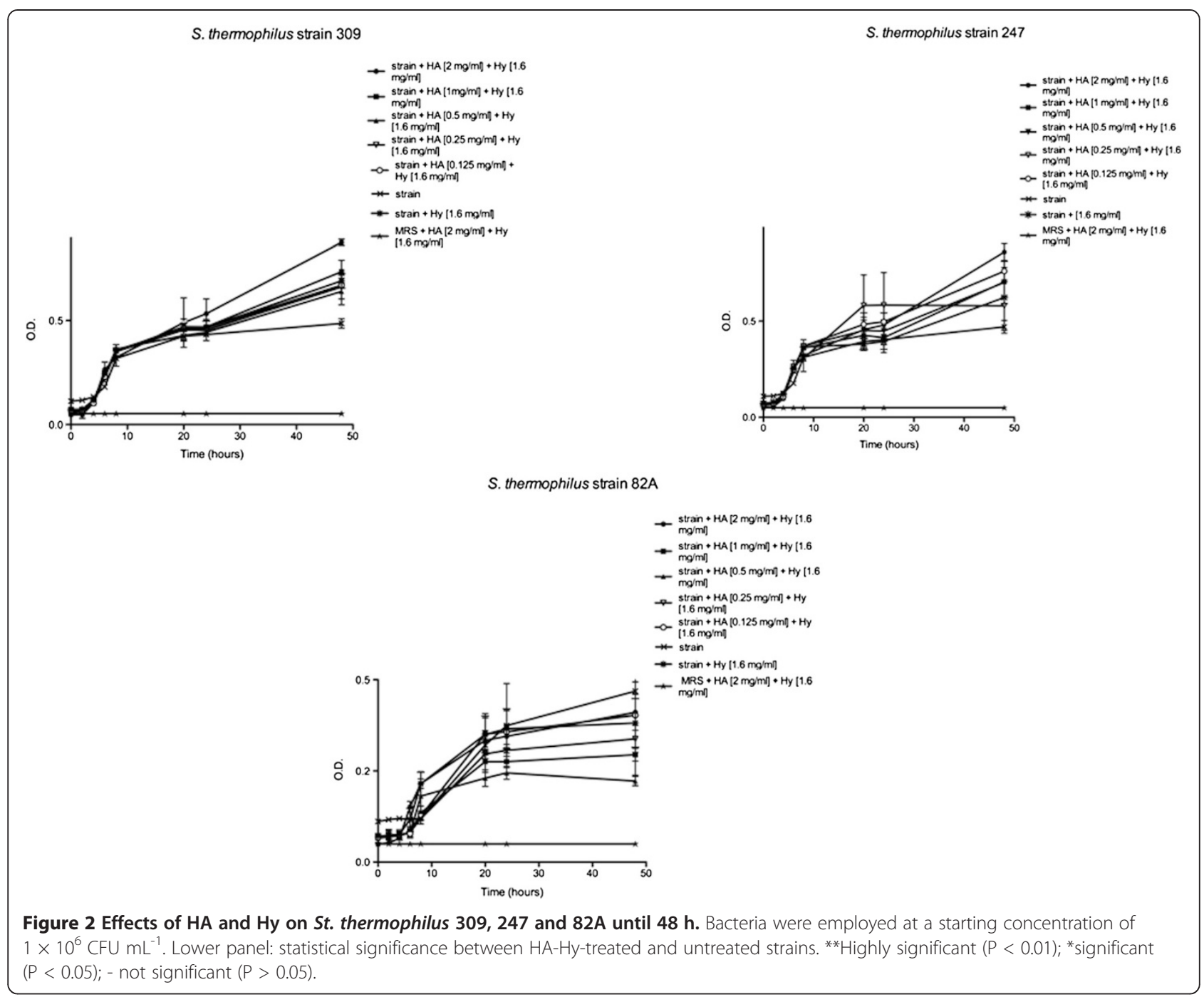

0.0625 up to $4 \mathrm{mg} \mathrm{ml}^{-1}$ for a total of 7 levels of exposure. $50 \mu \mathrm{l}$ of each dilution were loaded into wells in MRS agar plates seeded with tested strains. $\mathrm{pH}$ values of HA solutions were evaluated by means of $\mathrm{pH}$-meter (Beckman PHI43). LAB tested are reported in Table 1.

Tolerance to HA of strain $L b$. rhamnosus LbGG (ATCC) was also evaluated. Briefly, strain was subcultured twice in MRS (incubation at $30^{\circ} \mathrm{C}$ ). Cells in early stationary phase $\left(7.91 \pm 0.29 \log \mathrm{CFU} \mathrm{ml} \mathrm{m}^{-1}\right)$ were collected by centrifugation (6.500 rpm, $10 \mathrm{~min})$, washed once with sterile Ringer solution (Oxoid) and resuspended in the same saline. $200 \mu \mathrm{l}$ of sterile water solutions of HA $(0.0625,0.125,0.25,0.5,1,2,4$ and $8 \mathrm{mg} \mathrm{ml}^{-1}$ ) were added to $200 \mu \mathrm{l}$ of cell suspensions. Positive control was realized by adding $200 \mu \mathrm{l}$ of sterile saline instead of HA. After $30 \mathrm{~min}$ of incubation at $37^{\circ} \mathrm{C}$, living cells were enumerated by drop counting method (Collins et al., 1989) on MRS agar plates, followed by incubation for $72 \mathrm{~h}$ at $37^{\circ} \mathrm{C}$.
Effect of HA on Lb.GG tolerance to simulated gastric juice The effect of HA on LbGG tolerance to simulated gastric juice was determined according to the procedure reported by Michida et al. (2006) [22]. Briefly, cells were harvested from cultures in exponential phase of growth by centrifugation $(6.500 \mathrm{rpm}, 10 \mathrm{~min})$, washed twice with sterile saline $(0.5 \%, \mathrm{w} / \mathrm{v})$, and resuspended in the same sterile saline. Simulated gastric juice was prepared daily by suspending pepsin $(1: 10000, \mathrm{ICN})$ in sterile saline $(0.5 \%, \mathrm{w} / \mathrm{v})$ to a final concentration of $3 \mathrm{~g} \mathrm{l}^{-1}$ and adjusting the $\mathrm{pH}$ to 2.00 with concentrated $\mathrm{HCl}$ using a $\mathrm{pH}$ meter. Aliquots $(0.2 \mathrm{ml})$ of the cell suspensions were transferred to a $2.0 \mathrm{ml}$ capacity Eppendorf tube, mixed with $0.3 \mathrm{ml}$ of sterile water solutions of $\mathrm{HA}$ $\left(0.125,0.25,0.5,1,2,4\right.$, and $\left.8 \mathrm{mg} \mathrm{ml}^{-1}\right)$ and finally mixed with $1.0 \mathrm{ml}$ of simulated gastric. After incubation at $37^{\circ} \mathrm{C}$ for $90 \mathrm{~min}$, cells viability was assayed by drop counting method [23] on MRS agar plates (incubation for $72 \mathrm{~h}$ at $30^{\circ} \mathrm{C}$ ). 


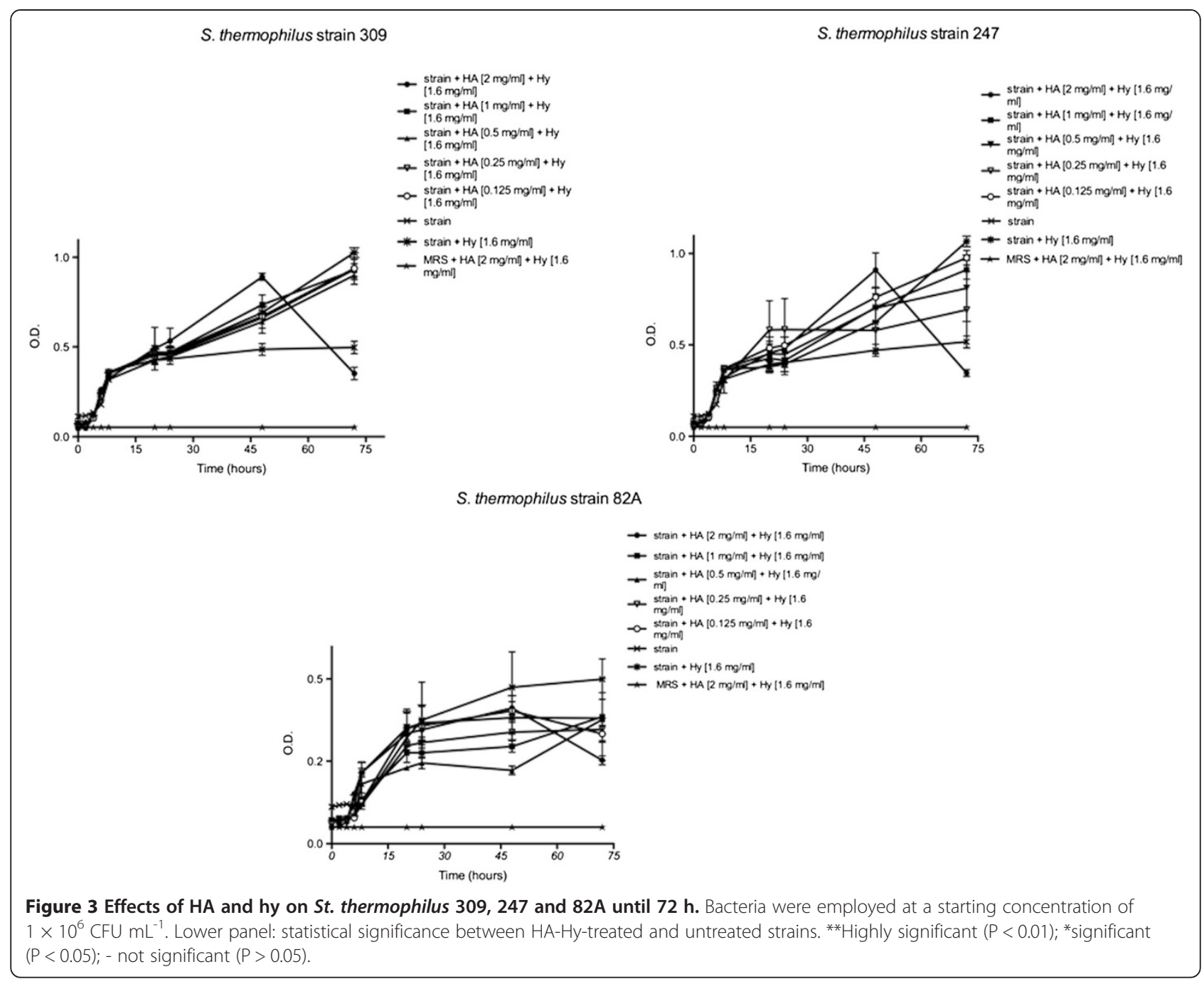

LAB's capability to utilize HA and its precursors as carbon sources

Acid formation by D-glucuronic acid, N-acetyl-D glucosamine, and HA was evaluated in MRS broth without glucose and meat extract with $2 \%$ added carbohydrates, as filter sterilized water solutions, and $0 \cdot 004 \%$ chlorophenol red. Media were inoculated with cell suspensions in sterile saline solution (about $6 \log \mathrm{CFU} \mathrm{ml} \mathrm{m}^{-1}$ ). Tests were performed on three urease positive St. thermphilus strains, namely 309, 82A and 247, and LbGG.

\section{Assessment of HA and Hy effect on LAB strains}

The effect of HA and HA in combination with Hy was evaluated on three St. thermophilus urease positive strains $(309,247$, and 82A). The assay was performed in 96-well microplates (Corning Inc., NY, USA). Firstly, $200 \mu \mathrm{l}$ of $\mathrm{HA}+\mathrm{MRS}\left[4,2,1,0,5\right.$ and $\left.0.25 \mathrm{mg} \mathrm{ml}^{-1}\right]$ were added in triplicate in each plate. Then $10 \mu \mathrm{l}$ of LAB cell suspensions (working concentrations of about $1 \times$ $10^{6} \mathrm{CFU} \mathrm{m} \mathrm{m}^{-1}$ ) in sterile saline solution were added.
Uninoculated MRS was used as control. Plates were incubated at $37^{\circ} \mathrm{C}$ in an incubator (Ekort 1500, Angelantoni industrie, Milano, Italy). The O.D. values were measured at a wavelength of $595 \mathrm{~nm}$ at $0,2,4,6,8,20$, 24 and 48 hours by means of a microplate reader (Tecan, Austria).

For the evaluation of HA-Hy effect, the procedure above described was repeated by adding to each well $100 \mu \mathrm{l}$ of $\mathrm{Hy}\left[1,8 \mathrm{mg} \mathrm{ml}^{-1}\right.$ in a saline solution] and $10 \mu \mathrm{l}$ of each strain (about $1 \times 10^{6} \mathrm{CFU} \mathrm{m}{ }^{-1}$ ). O.D. values were measured at $0,2,4,6,8,20,24,48$ and $72 \mathrm{~h}$ of incubation at $37^{\circ} \mathrm{C}$.

\section{Data analysis}

Data obtained from the O.D. readings were used to draw charts where O.D. was expressed as a function of time. Each point of the curves is the average value of three replicates (subtracted of the blank) performed in the same experimental conditions. Statistical analyses were performed at $2 \mathrm{~h}$ intervals. At each time, analysis of 
variance (ANOVA) and Bonferroni post hoc test were carried out to assess overall differences in O.D. readings obtained from different strains in relation to the control.

\section{Competing interests}

The authors declare that they have no competing interests.

\section{Authors' contributions}

$A D C$ and $R E$ developed and performed the experiments by dynamic light scattering and drafted the manuscript. MA did the assays about MIC to HA, HA utilization and strains' resistance to simulated gastric juice. MB and BP provided scientific orientation and revised the manuscript. All authors read and approved the final manuscript.

\section{Author details}

'Dipartimento di Chirurgia Generale e Specialità Chirurgiche, Università degli Studi di Modena e Reggio Emilia, via del pozzo 71 41124, Modena, Italy. ${ }^{2}$ Istituto di Scienze dell'Alimentazione, ISA-CNR, Via Roma, 64, 83100, Avellino, Italy. ${ }^{3}$ Dipartimento di Scienze della vita, Università degli Studi di Modena e Reggio Emilia, Via Campi 287, 41125, Modena, Italy.

Received: 15 April 2013 Accepted: 25 October 2013

Published: 4 November 2013

\section{References}

1. Maharjan AS, Pilling D, Gomer RH: High and low molecular weight hyaluronic acid differentially regulate human fibrocyte differentiation. PLoS One 2011, 6(10):1-10.

2. Murai T, Kawashima H: A simple assay for hyaluronidase activity using fluorescence polarization. Biochem Biophys Res Commun 2008, 376:620-624.

3. Toole BP: Hyaluronan and its binding proteins the hyaladherins. Curr Opin Cell Biol 1990, 2:839-844.

4. Murai T, Sougawa N, Kawashima H, Yamaguchi K, Miyasaka M: CD44chondroitin sulfate interactions mediate leukocyte rolling under physiological flow conditions. Immunol Lett 2004, 93:163-170.

5. Kawashima $\mathrm{H}$ : Roles of sulfated glycans in lymphocyte homing. Biol Pharm Bull 2006, 29:2343-2349.

6. Masuko K, Murata M, Yudoh K, Kato T, Nakamura H: Anti-inflammatory effects of hyaluronan in arthritis therapy: Not just for viscosity. Int $J$ Gen Med 2009, 2:77-81.

7. Schulz A, Vestweber AM, Dressler D: Anti-inflammatory action of a hyaluronic acid-chondroitin sulfate preparation in an in vitro bladder model. Aktuelle Urol 2009, 40(2):109-112.

8. Ardizzoni A, Neglia RG, Baschieri MC, Cermelli C, Caratozzolo M, Righi E, Palmieri B, Blasi E: Influence of hyaluronic acid on bacterial and fungal species, including clinically relevant opportunistic pathogens. J Mater Sci Mater Med 2011, 22:2329-2338.

9. Krasiński $R$, Tchórzewski H, Lewkowicz P: Antioxidant effect of hyaluronan on polymorphonuclear leukocyte-derived reactive oxygen species is dependent on its molecular weight and concentration and mainly involves the extracellular space. Postepy Hig Med Dosw 2009, 63:205-212.

10. Rodrigues SV, Acharya AB, Bhadbhade S, Thakur SL: Hyaluronan-containing mouthwash as an adjunctive plaque-control agent. Oral Health Prev Dent 2010, 8(4):389-394.

11. de Azeredo LAl, Leite SGF, Freire DMG, Benchetrit LC, Coelho RRR Proteases from actinomycetes interfere in solid media plate assays of hyaluronidase activity. J Microbiol Methods 2001, 45:207-212.

12. Gault DT: Extravasation injuries. Br J Plast Surg 1993, 46:91-96.

13. Smith $\mathrm{KJ}$, Skelton $H G$, Turiansky G, Wagner KF: Hyaluronidase enhances the therapeutic effect of vinblastine in intralesional treatment of Kaposi's sarcoma. J Am Acad Dermatol 1997, 36:239-242.

14. Ozegowski JH, Presselt N, Härtl A, Bocker T, Sänger J, Schmidt A, Willing $K$, Müller PJ: Anti-atherosclerotic effect of microbial hyaluronate lyase from group B streptococci. Pharmacology 2008, 63(8):601-605.

15. Kreil G: Hyaluronidases-a group of neglected enzymes. Protein Sci 1995, 4:1666-1669.

16. Aponte M, Fusco V, Andolfi R, Coppola S: Lactic acid bacteria occurring during manufacture and ripening of provolone del Monaco cheese: detection by different analytical approaches. Int Dairy J 2008, 18:403-413.
17. Aponte M, Blaiotta G, La Croce F, Mazzaglia A, Farina V, Settanni L, Moschetti G: Use of selected autochthonous lactic acid bacteria for Spanish-style table olive fermentation. Food Microbiol 2010, 30:8-16.

18. Blaiotta G, Di Capua M, Coppola R, Aponte M: Production of fermented chestnut purees by lactic acid bacteria. Int J Food Microbiol 2012, 158:195-202.

19. Blaiotta G, Sorrentino A, Ottombrino A, Aponte M: Short communication: technological and genotypic comparison between streptococcus macedonicus and streptococcus thermophilus strains coming from the same dairy environment. J Dairy Sci 2011, 94:5871-5877.

20. Corcoran BM, Stanton C, Fitzgerald GF, Ross RP: Growth of probiotic lactobacilli in the presence of oleic acid enhances subsequent survival in gastric juice. Microbiology 2007, 153:291-299.

21. Starr CR, Engleberg NC: Role of Hyaluronidase in subcutaneous spread and growth of group a streptococcus. Infect Immun 2006, 74(1):40-48.

22. Michida H, Tamalampudi S, Pandiella SS, Webb C, Fukuda H, Kondo A: Effect of cereal extracts and cereal fiber on viability of lactobacillus plantarum under gastrointestinal tract conditions. Biochem Eng J 2006, 28:73-78.

23. Collins $\mathrm{CH}$, Lyne PM, Grange JM: Counting microorganism. In Microbiological Methods. Edited by Collins CH, Lyne PM, Grange JM. Oxford, UK: Butterworth-Heinemann; 1989:127-140.

doi:10.1186/1471-2180-13-243

Cite this article as: Di Cerbo et al: Comparison of the effects of hyaluronidase and hyaluronic acid on probiotics growth. $B M C$ Microbiology 2013 13:243.

\section{Submit your next manuscript to BioMed Central and take full advantage of:}

- Convenient online submission

- Thorough peer review

- No space constraints or color figure charges

- Immediate publication on acceptance

- Inclusion in PubMed, CAS, Scopus and Google Scholar

- Research which is freely available for redistribution 